Department of Economics and Marketing Discussion Paper No.29

\title{
New Methodology for the Ecological Footprint with an Application to the New Zealand Economy
}

\author{
Kathryn B Bicknell \\ Richard J Ball \\ Ross Cullen \\ Hugh R Bigsby
}

\author{
April 1997 \\ Department of Economics and Marketing \\ PO Box 84 \\ Lincoln University \\ CANTERBURY \\ Telephone No: (64) (3) 3252811 \\ Fax No: (64) (3) 3253847 \\ E-mail: bicknelk@lincoln.ac.nz
}

ISSN 1173-0854

ISBN 1-877176-06-0 


\begin{abstract}
Sustainable development has become a primary objective for many countries throughout the world since the late 1980's. A major difficulty associated with sustainable development objectives, however, is the absence of reliable indicators to measure progress towards the goal of sustainability. The "ecological footprint", developed by William Rees and Mathis Wackernagel, provides an estimate of the land area necessary to sustain current levels of resource consumption for a given population. On an aggregate basis, the ecological footprint may be compared with the amount of ecologically productive land available to give an indication of whether consumption patters are likely to be sustainable.

This paper proposes the use of a modified form of input-output analysis to calculate the ecological footprint. The input-output approach provides a consistent means of calculating an ecological footprint using data collected as part of the system of national accounts in most developed countries. In addition, it makes explicit the link between the level of economic activity in a country and its corresponding impact on the environment. An application of this methodology to New Zealand indicates that it takes 3.49 hectares of ecologically productive land per year to sustain the average New Zealander's current level of consumption.
\end{abstract}

\title{
KEYWORDS
}

Ecological footprint, input-output methodology, sustainability, environmental impact.

\section{Acknowledgement}

The authors wish to thank Landcare Research New Zealand Limited for providing the funding for this research. 


\section{Contents}

List of Tables

1. Introduction 1

2. Methodology . 2

2.1 Previous Work 2

2.2 Modification to the Existing Methodology 4

2.2.1 Domestic Land 5

2.2.2 Open Economy 9

3. Estimating New Zealand's Ecological Footprint 12

4. Results 13

5. Assumptions and Limitations 15

6. Conclusions 18

$\begin{array}{ll}\text { References } & 20\end{array}$ 


\section{List of Tables}

1. Transaction for a Three Sector Economy 5

2. Matrix of Technical Coefficients for Three Sector Economy 6

3. Leontief Inverse Matrix for Three Sector Economy 6

4. Land:Output Ratios for the Three Sector Economy 7

5. Matrix of Direct Plus Indirect Land Requirements for Three Sector Economy 7

6. Calculation of the Ecological Footprint for Three Sector Economy 8

7. Calculation of the Final Demand Component for Imported Land 10

8. Value of Imports By Sector 10

9. Land Embodied in Goods Imported by Industrial Sectors 11

10. Ecological Footprint Calculations for Hypothetical Open Economy 11

11. New Zealand's Per Capita Ecological Footprint 13

12. International Comparisons 14

13. New Zealand's Ecological Balance of Trade 15 


\section{Introduction}

The ecological footprint has been defined as the amount of productive land required to support the consumption of a given population indefinitely. The concept was developed by William Rees and Mathis Wackernagel at the University of British Colombia's School of Community and Regional Planning. An implicit assumption underlying ecological footprint analysis is that long run economic welfare depends upon meeting the criteria of strong sustainability. In other words, sustainability requires the maintenance of natural capital both as a source for inputs and as a sink for waste. Therefore, consumption is ultimately dependant on the availability of renewable resources if sustainability is to be achieved.

The ecological footprint is closely related to the ecological concept of carrying capacity, which is the population of a given species that can be supported indefinitely in a defined habitat without permanently damaging the ecosystem on which it is dependent. Ecological footprints are denominated in hectares per capita, whereas carrying capacity is generally expressed in units of individuals per hectare, making one concept the inverse of the other. The ecological footprint can be readily adapted to incorporate trade, however, making it a more appropriate concept to apply to human populations (Pearce, 1994; Wackernagel and Rees, 1996). Unlike carrying capacity, the ecological footprint captures all the bio-physical impacts of a given community regardless of where those impacts occur.

In effect the ecological footprint provides a 'snapshot' of the resources required to support consumption given available technology and processes. As such, the ecological footprint can be compared with the land available to support human consumption to provide a static indicator of sustainability. Any change in technology or resource use patterns could then be incorporated in subsequent estimates of the ecological footprint.

This paper presents a novel way of calculating an ecological footprint using input-output methodology. The primary advantage of the input-output framework is that it provides a standard method of analysis that can be updated or applied to alternative populations in a uniform manner. The methodology is described in detail in Section Two, and then applied to the New Zealand economy in Section Three. The results are presented and compared with international estimates in Section Four. The assumptions and limitations of the input-output 
based methodology are discussed in Section Five, and the paper concludes with summary statements in Section Six.

\section{Methodology}

\subsection{Previous Work}

The methodology developed by the UBC researchers is outlined in two earlier publications (Wackernagel et al., 1993; Wackernagel and Rees, 1996). To facilitate an already complex analysis, Wackernagel et al. construct a consumption - land-use matrix with five major consumption categories and six major land use categories. Consumption categories include Food, Housing, Transportation, Consumer Goods, and Services, while land use categories include Energy Land, Built (Degraded) Environment, Gardens, Cropland, Pasture, Managed Forest. The objective of this previous work is to account for all of the land that is appropriated in the production and maintenance of every good and service consumed by a particular community. A carton of milk, for example, requires pasture land to support dairy cattle, forestry land to produce the fibre for packaging, and degraded land for transport and final sales. In addition, 'energy land' is embodied in every stage of the production process.

The calculation procedure proposed by Wackernagel et al. involves using consumption and population statistics to calculate the “average person's” annual consumption for several items in each of the consumption categories. The area appropriated by each person can then be calculated by dividing the annual per capita consumption by the average annual productivity or yield for each item consumed. The total per capita ecological footprint is obtained by summing all ecosystem areas appropriated for each item consumed during a particular time period.

Prior work suggests that 'energy land' accounts for over fifty percent of the total ecological footprint for developed countries (Wackernagel and Rees, 1996). This component represents the amount of land required to sustainably support energy use. Energy land can be estimated under a variety of assumptions. One alternative involves the production of a biologically produced substitute for fossil fuel such as ethanol or methanol. Prior studies, reported in 
Wackernagel and Rees (1996), suggest an energy to land ratio of 80 to 150 gigajoules per hectare per year for these fuels. A second alternative is to calculate the land area needed to sequester the $\mathrm{CO}_{2}$ emitted from burning fossil fuel. Wackernagel and Rees (1996) cite earlier work which suggests that on average one hectare of forest can sequester the $\mathrm{CO}_{2}$ emissions generated by the consumption of 100 gigajoules of fossil fuel each year. A final alternative is to determine the land area required to rebuild a substitutable form of natural capital at the same rate the fossil fuel is being depleted. Estimates suggest that on average one hectare of forest can accumulate 80 gigajoules of recoverable biomass energy per year in the standing timber.

Data to support the calculation of Canada's ecological footprint came from a wide variety of sources (Wackernagel et al, 1993; Wackernagel and Rees, 1996). Government publications with national statistics on consumption and trade provided most of the consumption data. Productivity and yield data were obtained from a wide range of studies, and generally incorporated world average productivity statistics to reflect the increasing reliance on multilateral trade flows. We are of the opinion, however, that this practice obscures the important gains that may result from an ecological comparative advantage. Although higher yields will not imply smaller footprints if the underlying technology is particularly energy intensive, land requirements for every population could be reduced by allowing production to flow to regions with "land sparing” production technologies.

Wackernagel and Rees (1996) present a number of specific applications of ecological footprint analysis. Not only do they provide estimates of ecological footprints for a variety of countries, but they also use footprint analysis to address policy questions. An estimate of the ecological footprint for the average Canadian, for example, has been calculated at 4.27 hectares per person. Similar figures for the Netherlands, the United States and India are 3.32, 5.1 and 0.38, respectively. Clearly this sort of analysis has the potential to reveal distributional issues. A comparison of each country's aggregate footprint with the corresponding land available also indicates that most populations are running an "ecological deficit”. Sensitivity analysis demonstrates how specific technologies or lifestyle choices may reduce the impact that a particular region has on the environment. 


\subsection{Modification to the Existing Methodology}

The detailed methodology presented by Wackernagel et al. (1993) to estimate Canada's ecological footprint relied upon an eclectic mixture of data sources, drawing on research from several countries and spaning a 30 year time horizon. Consequently, their results can not be easily reproduced or meaningfully compared across time or between populations. Unfortunately if a measure is not consistently applied and regularly updated, variations in the results may be attributable to variations in the method, rather than the phenomena it claimed to measure (Bartelmus, 1994). The goal of this research was therefore to initiate a more integrated approach to the calculation of an ecological footprint, using established databases that are adequately maintained and regularly updated in most developed countries. To achieve this objective a modified form of input-output analysis was developed using data collected by Statistics New Zealand and Valuation New Zealand.

Input-output analysis, developed in the 1930s and 1940s by Wassily Leontief and expanded considerably since that time, is a well known economic tool that can be used to study how various sectors of a regional or national economy are related. Although input-output models are based on economic transactions tables denominated in dollars, Leontief (1970) pointed out that physical by-products of production processes, such as pollution, are also tied directly to the economic system which generates them. The links between final demand, the production of goods and services, and the production of undesirable by-products can therefore be explored by input-output methods.

The methodology described below was used to calculate the ecological footprint for New Zealand. This approach facilitates a detailed breakdown of the agricultural, forest and degraded land embodied in the goods and services consumed in any country that maintains standard transaction tables. Garden land accounts less than one half of one percent of Canada's ecological footprint, and has therefore been excluded from this analysis. The estimate of land required to support energy consumption was calculated using data provided by Dr John Peet, Department of Chemical and Process Engineering, University of Canterbury. 
Essentially, the method requires the calculation of standard input-output coefficients, which are subsequently multiplied by a land to value-of-output ratio for each industrial sector. Elements of the resulting matrix, expressed in hectares per dollar of output, can be multiplied by the final demand vector to determine the land required to provide for a certain level of consumption. The details of the method, including adjustments for trade, are illustrated using a simplified three industry economy (Table 1).

Table 1

Transaction Table for a Three Sector Economy ${ }^{\text {a }}$

\begin{tabular}{|c|c|c|c|c|c|c|}
\hline & Sector 1 & Sector 2 & Sector 3 & $\begin{array}{c}\text { Final } \\
\text { Demand }\end{array}$ & Exports & Total Output \\
\hline Sector 1 & 45 & 15 & 8 & 55 & 25 & 148 \\
\hline Sector 2 & 23 & 30 & 42 & 25 & 20 & 140 \\
\hline Sector 3 & 15 & 25 & 10 & 40 & 5 & 95 \\
\hline Value Added & 45 & 55 & 30 & 20 & & \\
\hline Imports & 20 & 15 & 5 & 10 & & \\
\hline Total inputs & 148 & 140 & 95 & & & \\
\hline Land Input $^{\mathrm{b}}$ & 14,000 & 2,000 & 100 & & & \\
\hline
\end{tabular}

a All values with the exception of the land input are expressed in millions of dollars. b Hectares

The technical coefficient matrix (commonly labelled the ' $A$ ' matrix) is derived from the transaction table by dividing relevant elements in the industrial columns by the corresponding output for that sector. The result for this simple example is a 3x3 matrix of technical coefficients which represent the amount of inputs from sector $\mathrm{i}$ (in dollars) needed to increase output in sector $\mathrm{j}$ by one dollar (Table 2). Sector 1, for example, must purchase approximately $16 \mathbb{4}$ worth of inputs directly from Sector 2 in order to increase output by $\$ 1$. Direct input purchases such as these, derived ultimately from the demand for final goods and services, initiate a chain of economic activity throughout the productive sectors of the economy which are captured by the Leontief inverse matrix. 
Table 2

Matrix of Technical Coefficients for Three Sector Economy

\begin{tabular}{||lccc||}
\hline & Sector 1 & Sector 2 & Sector 3 \\
\cline { 2 - 4 } Sector 1 & 0.304 & 0.107 & 0.083 \\
Sector 2 & 0.155 & 0.214 & 0.442 \\
Sector 3 & 0.101 & 0.179 & 0.105 \\
\hline
\end{tabular}

The Leontief inverse matrix is calculated by inverting the matrix that results when the matrix of technical coefficients is subtracted from an identity matrix of the same dimension. Mathematically the Leontief inverse matrix is expressed as (I - A $)^{-1}$. Each entry in this matrix represents the amount of economic activity generated in industry $i$, both directly and indirectly, to increase output in industry $\mathrm{j}$ by $\$ 1$. Returning to our previous example, a $\$ 1$ increase in final demand for Sector 1 will ultimately require $45 \$$ of output from Sector 2 (Table 3).

Table 3

Leontief Inverse Matrix for Three Sector Economy

\begin{tabular}{||cccc||}
\hline & Sector 1 & Sector 2 & Sector 3 \\
\cline { 2 - 4 } Sector 1 & 1.539 & 0.273 & 0.280 \\
Sector 2 & 0.453 & 1.514 & 0.791 \\
Sector 3 & 0.264 & 0.333 & 1.307 \\
\hline
\end{tabular}

In conventional input-output analysis, the transaction table is denominated in dollars, and the resulting technical coefficients and multipliers are expressed in dollars per dollar. To estimate the land area required to increase output in each sector by a particular dollar amount these financial multipliers must be expressed in terms of land area. The conversion factors required are obtained by dividing total land area used directly in each sector by the total output (in dollars) of that sector. Because the transaction table is expressed in millions of dollars, the resulting ratios represent the number of hectares required to increase output by $\$ 1,000,000$ in each sector. The total land requirement for Sector 1, for example, is 94.59 hectares per 
million dollars worth of output. The remaining sectors are considerably less land intensive (Table 4).

The total (direct plus indirect) land requirements can then be obtained by pre-multiplying the Leontief inverse matrix by a diagonal matrix containing the land coefficients. The results for the hypothetical three sector economy are presented in Table 5. A \$1,000,000 increase in final demand for Sector 1 ultimately requires 145.67 hectares of land employed in Sector 1, 6.47 hectares of Sector 2 land, and 0.28 hectares of land devoted to production in Sector 3 . Column totals in Table 5 represent the total number of hectares required to increase output in each sector by $\$ 1,000,000$. Current production technology, therefore, requires a total (direct plus indirect) land input of 152.42 hectares for each \$1 million of output in Sector 1.

Table 4

Land: Output Ratios for the Three Sector Economy

\begin{tabular}{||cc|}
\hline & $\begin{array}{c}\text { Land Coefficient } \\
\text { (ha/\$million output) }\end{array}$ \\
\cline { 2 - 3 } Sector 1 & 94.59 \\
Sector 2 & 14.29 \\
Sector 3 & 1.05 \\
\hline
\end{tabular}

Table 5

Matrix of Direct Plus Indirect Land Requirements for Three Sector Economy

\begin{tabular}{||cccc||}
\hline & Sector 1 & Sector 2 & Sector 3 \\
\cline { 2 - 4 } Sector 1 & 145.67 & 25.82 & 26.49 \\
Sector 2 & 6.47 & 21.64 & 11.30 \\
Sector 3 & 0.28 & 0.35 & 1.37 \\
Total $^{\mathrm{a}}$ & 152.42 & 47.81 & 39.16 \\
\hline
\end{tabular}

a Total land required per $\$ 1,000,000$ increase in final demand. 
The strength of this analysis is that it facilitates a deeper appreciation of land requirements for industries that do not initially appear to be particularly land intensive. For example, although a \$1,000,000 increase in final demand for Sector 3 only requires a direct land input of 1.05 hectares, backward linkages with other sectors of the economy mean that 39.16 hectares are ultimately required to fulfil this increase in final demand. This implies a 'land multiplier' of 39.16/1.05, or 37.29 for Sector 3.

The land required to meet the current level of domestic final demand for each sector can be derived by multiplying the total land input requirements for each industry (column totals in Table 5) by the corresponding component of the final demand vector. Results for the hypothetical economy are presented in Table 6. The ecological footprint for the entire economy is converted to a per capita ecological footprint by dividing by the total population. This is shown in the final column of Table 6 using a population of 3,500 individuals.

Table 6

Calculation of the Ecological Footprint for Three Sector Economy

\begin{tabular}{||ccccc||}
\hline \hline & $\begin{array}{c}\text { Land } \\
\text { Requirement }\end{array}$ & $\begin{array}{c}\text { Final Demand } \\
\text { (Domestic) }\end{array}$ & $\begin{array}{c}\text { Total } \\
\text { Footprint }\end{array}$ & $\begin{array}{c}\text { Per Capita } \\
\text { Footprint }\end{array}$ \\
\cline { 2 - 5 } Sector 1 & 152.42 & 55 & 8,383 & 2.40 \\
Sector 2 & 47.81 & 25 & 1,195 & 0.34 \\
Sector 3 & 39.16 & 40 & 1,566 & 0.45 \\
Total & & & & 3.19 \\
\hline
\end{tabular}

It is worth emphasising that if the ecological footprint incorporates technology which is not sustainable it will give a distorted picture of our impact on the environment. Burning fossil fuel, for example, represents the depletion of an exhaustible resource, and results in the production of an undesirable by-product. In addition, many current agricultural practices compact or erode the soil, thus compromising the land's future capacity to generate food and fibre. Certain consumption activities and industrial processes may also result in the generation of long-lived toxic wastes that threaten the environment and can therefore not be carried out indefinitely. The totals presented in Table 6 do not account for such unsustainable practices. 
Energy land represents the only attempt to incorporate unsustainable practices into the ecological footprint. Although we have not included it in our estimate for the hypothetical three sector economy, energy land has been incorporated into the empirical analysis for New Zealand (presented in Section Three). Energy land was calculated using a similar input-output based technique whereby total (direct and indirect) energy multipliers are derived for every sector of the economy (Bullard, Penner and Pilati, 1976). The total energy embodied in goods and services consumed domestically can be calculated by combining energy multipliers and a vector of final demand. To express these totals in a land equivalent basis, they are divided by a scalar which represents the land's capacity to either create energy in a sustainable manner or absorb $\mathrm{CO}_{2}$ (the primary by-product created by burning fossil fuel).

\subsubsection{Open Economy}

In a closed economy the above analysis would be sufficient to account for the productive land incorporated in the goods and services consumed by our hypothetical economy. Inter-regional trade, however, enables almost every human population to consume goods which embody ecological resources located beyond their home region. Adjustments must therefore be made to subtract the domestic land area used to produce exports, and incorporate the overseas land area required to support imports. In other words, the ecological footprint should reflect the impact that a given population has on ecological resources, wherever that impact may occur.

As government statistics generally provide detailed information on the balance of trade, exports can be excluded simply by subtracting them from final demand. Lack of information on the land intensity of overseas production, however, makes the analysis of imports more difficult. Assuming similar production technologies, the land embodied in goods and services imported directly to final demand can be calculated by multiplying the value of imports by its corresponding domestic land multiplier.

The procedure for calculating the land embodied in imports that are used as intermediate goods or services is more complex, and requires additional simplifying assumptions. The process begins by acquiring a detailed breakdown of imports to each productive sector. Data for the hypothetical economy is displayed in Table 8, where columns correspond to the domestic sector and rows correspond to the overseas sector. Sector 2 of the domestic economy, for example, imports $\$ 2$ million worth of goods from the overseas equivalent of 
domestic Sector 3. This information, which is denominated in millions of dollars, must then be converted to hectares. Once again, this would ideally involve detailed information from each of the countries providing intermediate inputs. Unfortunately data limitations will almost undoubtedly require the use of information from the domestic economy.

Figures in Table 9, expressed as hectares of overseas land, have been derived by premultiplying the matrix of imports by the vector of direct plus indirect land requirements for the three sector economy. Elements in the resulting vector represent the total amount of overseas land embodied in goods imported by each industrial sector. Note the implicit assumption that the goods which are imported by the industrial sectors are essentially final or finished goods. If the goods are in fact in a relatively "raw" state, this assumption will bias the footprint calculation upwards.

Table 7

Calculation of the Final Demand Component for Imported Land

\begin{tabular}{||cccc||}
\hline & $\begin{array}{c}\text { Land } \\
\text { Requirement }\end{array}$ & $\begin{array}{c}\text { Final Demand } \\
\text { (Imports) }\end{array}$ & $\begin{array}{c}\text { Ecological } \\
\text { Footprint }\end{array}$ \\
\cline { 2 - 4 } Sector 1 & 152.42 & 7 & 0.21 \\
Sector 2 & 47.81 & 3 & 0.03 \\
Sector 3 & 39.16 & 0 & 0.00 \\
Total & & & 0.24 \\
\hline
\end{tabular}

Table 8

Value of Imports by Sector (millions of dollars)

\begin{tabular}{||cccc||}
\hline & Sector 1 & Sector 2 & Sector 3 \\
\cline { 2 - 4 } Sector 1 & 5 & 5 & 0 \\
Sector 2 & 15 & 8 & 5 \\
Sector 3 & 0 & 2 & 0 \\
\hline
\end{tabular}


Finally, it is important to recognise that some of this imported land will be supporting exports, which contribute to the ecological footprint of this country's trading partners. Only a fraction, therefore, of the total land embodied in imports will support domestic consumption. The totals in the second column of Table 9 are therefore adjusted by multiplying them by the fraction of final demand that is consumed domestically for each sector. Approximately sixtynine percent of the output of Sector 1 which flows to final demand, for example, is consumed domestically. This implies that 1,016.98 of the total 1,479.25 hectares embodied in imports to Sector 1 are contributing towards the domestic ecological footprint. Other sectors have been adjusted accordingly.

Table 9

Land Embodied in Goods Imported by Industrial Sectors (hectares)

\begin{tabular}{||lccc||}
\hline \hline & $\begin{array}{c}\text { Land embodied } \\
\text { in imports }\end{array}$ & $\begin{array}{c}\text { Land supporting domestic } \\
\text { ecological footprint }\end{array}$ & $\begin{array}{c}\text { Expressed on a per- } \\
\text { capita basis }\end{array}$ \\
Sector 1 & $1,479.25$ & $1,016.98$ & 0.29 \\
Sector 2 & $1,222.90$ & 679.38 & 0.19 \\
Sector 3 & 239.05 & 212.49 & 0.06 \\
Total & $2,941.2$ & $1,908.85$ & 0.54 \\
\hline
\end{tabular}

Table 10

Ecological Footprint Calculations for Hypothetical Open Economy

\begin{tabular}{||cccc||}
\hline & Domestic Land & Imported Land & Ecological Footprint \\
\cline { 2 - 4 } Sector 1 & 2.40 & 0.50 & 2.9 \\
Sector 2 & 0.34 & 0.22 & 0.56 \\
Sector 3 & 0.45 & 0.06 & 0.51 \\
\cline { 2 - 4 } Total & $3.19(80.35 \%)$ & $0.78(19.65 \%)$ & 3.97 \\
\hline
\end{tabular}

Final results for this hypothetical economy demonstrate how much land is required to meet current levels of consumption, and provide an indication of how much land is imported from overseas (Table 10). The modified input-output analysis also allows the analyst to make 
comparisons between levels of final demand in various sectors. For example an additional $\$ 1,000,000$ spent in Sector 1 would increase the total ecological footprint by 0.045 hectares per capita, or 1.1\%. By contrast, the same expenditure directed towards Sector 3 would increase the footprint by 0.0118 hectares per capita, or $0.289 \%$. Statistics New Zealand provides data at a much lower level of aggregation, allowing for detailed analysis of 80 primary producing sectors. The next section is devoted to a discussion of how this methodology was used to calculate the ecological footprint for New Zealand.

\section{Estimating New Zealand's Ecological Footprint}

The calculation of New Zealand's ecological footprint by the modified input-output approach outlined above utilised an 80 sector transaction matrix produced by Statistics New Zealand. The 1991 table was used for this analysis as it contains the most up to date information available. A detailed matrix of import data was also obtained from Statistics New Zealand to facilitate the contribution of imported land to New Zealand's ecological footprint.

The land area used directly by forestry, conservation, and the agricultural sectors was readily obtained from the Official New Zealand Yearbook. These three types of land uses collectively account for over 94 percent of New Zealand's 27 million hectares. Data on the land area covered by roads (a component of degraded land) was available from Transit New Zealand (1994). Data for other land uses such as commercial buildings and residential dwellings, however, was not so easily obtained from published sources. A comprehensive database detailing land use by category was therefore purchased from Valuation New Zealand. Where possible this information was cross checked with other sources, such as zoning information, yearbook statistics, and previous research such as Barker (1978).

The calculation of the energy land component of the footprint utilised previous work by Dr John Peet and Mr James Baines. Peet and Baines employed a similar input-output approach (described in detail in Bullard, Penner and Pilati, 1976) to calculate energy multipliers from the 1991 input-output tables. The total energy required to support consumption was calculated by multiplying final demand by the vector of energy intensity multipliers Units of energy are then converted to a land area equivalent with an energy-to-land ratio. Wackernagel and Rees (1996) suggest using a factor of 100 gigajoules per hectare to reflect the area 
needed to sequester the $\mathrm{CO}_{2}$ emitted from burning fossil fuel. This figure is based on prior studies which suggest that on average a hectare of forest can sequester the $\mathrm{CO}_{2}$ emission generated by the consumption of 100 gigajoules of fossil fuel. Energy land embodied in imports and exports was calculated by multiplying the value of imports and exports by Peet and Baines’ energy multipliers, then applying the energy-to-land ratio.

Population statistics to express the ecological footprint on a per capita basis were obtained from the Official New Zealand Yearbook. In 1991 New Zealand had a population of $3,408,000$.

\section{Results}

To facilitate the comparison of our results with those published earlier, the final input-output related matrices have been condensed to correspond more closely with the land categories used by Wackernagel and Rees (1996). Agricultural land, for example, represents the land embodied in the output produced by sheep, beef and mixed livestock, dairy, horticulture, and all other farming sectors. The results are summarised in Table 11. Cell entries represent the ecologically productive land required per capita to satisfy current levels of domestic final demand. Recall that the input-output approach captures all backward linkages, so these figures include not only direct household consumption, but also the land 'embodied' in all of the input processes leading up to the final product.

Table 11

New Zealand's per Capita Ecological Footprint

\begin{tabular}{||cccccc||}
\hline $\begin{array}{c}\text { Agricultural } \\
\text { Land }\end{array}$ & $\begin{array}{c}\text { Forest } \\
\text { Land }\end{array}$ & $\begin{array}{c}\text { Degraded } \\
\text { Land }\end{array}$ & $\begin{array}{c}\text { Energy } \\
\text { Land }\end{array}$ & $\begin{array}{c}\text { Imported } \\
\text { Land }\end{array}$ & Total \\
\hline 1.41 & 0.28 & 0.36 & 0.53 & 0.91 & 3.49 \\
\hline
\end{tabular}

Using this method New Zealand's ecological footprint was calculated to be 3.49 hectares per person. A comparison with the overseas estimates reported by Wackernagel and Rees (Table 12) shows that New Zealand's ecological footprint is larger than the world average, but less than that of the US and Canada. Although differences in methodology mean that our results 
are not strictly comparable to estimates for other countries, it is interesting to reflect on how the consumption of energy land may differ among nations. Over 23\% of New Zealand's total ecological footprint can be attributed to the consumption of fossil fuel. Wackernagel and Rees (1996) indicate that energy land comprises 55\% of Canada's total ecological footprint. The figures for the Netherlands and India are 63\% and 13\%, respectively. New Zealand's relatively low energy component could be attributed to the structure of the economy, which is highly dependant on primary production rather than industrial production. Clearly the assumptions that are made about the productivity of alternative sources of energy or the ability of the natural environment to sequester $\mathrm{CO}_{2}$ will have a significant impact on the resulting ecological footprint.

Table 12

International Comparisons

\begin{tabular}{||lc||}
\hline \multicolumn{1}{||c||}{ Country } & Ecological Footprint \\
\hline United States $^{\mathrm{a}}$ & 5.1 \\
Canada $^{\mathrm{a}}$ & 4.27 \\
New Zealand & 3.49 \\
Netherlands $^{\mathrm{a}}$ & 3.32 \\
India $^{\mathrm{a}}$ & 0.38 \\
World Average $^{\mathrm{a}}$ & 1.8 \\
\hline \hline
\end{tabular}

a Source: Wackernagel and Rees (1996)

An advantage of the input-output approach is that it allows the analyst to explore the link between international trade and the ecological footprint. Using the methodology outlined in Section Two, we can determine how much land is being 'imported' from overseas via the consumption of imported goods and services. Our results suggest that 3,201,961 hectares, or over $26 \%$ of the total land embodied in the goods and services consumed in New Zealand is imported. Similarly, we can determine how much land is exported by multiplying our total domestic land and energy multipliers by the value of exports. This analysis suggests that almost 14 million hectares were embodied in the goods and services exported from New Zealand in 1991. Most of the land exported was agricultural land embodied in primary 
agricultural products. Given this country's comparative advantage in agricultural production it is not surprising that more land is exported from than imported to New Zealand.

Table 13

New Zealand's “Ecological Balance of Trade”

\begin{tabular}{|c|c|c|}
\hline & $\begin{array}{l}\text { Land Embodied in } \\
\text { Imports }\end{array}$ & $\begin{array}{c}\text { Land Embodied in } \\
\text { Exports }\end{array}$ \\
\hline Energy Land & 966,812 & \\
\hline Other & $2,136,149$ & \\
\hline Agricultural Land & & $10,896,297$ \\
\hline Forest Land & & 964,572 \\
\hline Degraded Land & & 237,908 \\
\hline Energy Land & & $1,677,843$ \\
\hline Total & $3,102,961$ & $13,776,620$ \\
\hline
\end{tabular}

New Zealand's national ecological footprint is 11,893,920 hectares. This represents approximately $64 \%$ of the total productive land in the country, including that owned by the Crown. New Zealand is therefore one of the few developed countries that is not running an "ecological deficit” to fuel it's own consumption. It is interesting to note, however, the land required for domestic consumption plus that required for export is slightly more than the ecologically productive land available within the country. This deficit surfaces once the energy land is added to the requirements for agricultural, forestry and domestic land.

\section{Assumptions and Limitations}

A number of assumptions have been incorporated into this analysis. Some of the assumptions are rooted in the proposed methodology, while others are associated with the broader concept of the ecological footprint itself. Assumptions only become limitations, however, when they compromise the integrity of the conclusions that are being drawn from the research. In this 
section we present a discussion of the critical assumptions associated with our analysis, and comment on the extent to which these assumptions may influence our conclusions.

The method presented in this paper relies on an input-output framework, and the usual assumptions and limitations of that technique apply to our calculation of New Zealand's ecological footprint. The assumption of homogeneity (that each industry produces a single product and all output uses the same processes and technology) may create problems for an individual who wishes to apply ecological footprint analysis to a particular firm, product or service. However, at a macro-level this assumption should not severely limit the application of this technique.

Input-output analysis also assumes linear production functions, which implies that inputs must be used in fixed proportions, and excludes the possibility of economies or diseconomies of scale. If the ecological footprint is being used as a general indicator of the effects of current consumption, the linearity assumption may not pose a problem. It becomes a limitation, however, if the transaction tables and their resulting multipliers are used as a forecasting tool.

A third limitation of the input-output technique is that the transaction tables generally exclude unpaid work. The value of most domestic work, for example, is not included in the initial tables. It would therefore not be appropriate to apply the methodology outlined in this paper if a significant amount of economic activity takes place outside the monetary economy. We do not anticipate that the exclusion of non-monetary activities will have a major impact on the size of New Zealand's ecological footprint.

The flow of goods and services throughout an economy generally involve physical goods. The transaction table which summarises these flows is, however, denominated in dollars. Using money as a numeraire facilitates the subsequent analysis, but if intersectoral prices differ greatly it may distort the physical linkages between industries. The figures in Table 1, for example, indicate that Sector 3 provides Sector 1 with \$15 million worth of goods, and Sector 2 with $\$ 25$ million worth of goods. If intersectoral prices are constant, we could infer from this that Sector 3 provides Sector 2 with 1.67 times more physical output than they provide for Sector 1. From an ecological footprint perspective, therefore, we would conclude that there is substantially more land embodied in the inputs that Sector 3 provides to Sector 2. If the nature of the Sector 3's output was such that they could charge Sector 2 a substantially 
higher price per unit than Sector 1, on the other hand, we would have drawn a false conclusion about the amount of land embodied in the goods transferred between sectors. This problem is closely related to the homogeneity assumption, and is a consequence of the aggregation process. It is important to note, however, that there are aggregation problems associated with Wackernagel and Rees’ original methodology as well.

The fixed land-to-output and energy-to-output ratios used for each industrial sector imply that output can not be changed substantially without altering the land and energy inputs. While these assumptions may be tenable (particularly applied to energy) for a shortrun analysis of a single country's economic activity, they are likely to create a problem when applied to imports. As mentioned in previous sections, if production flows to countries who use environmentally sensitive technology, trade may very well provide a means to reduce the global ecological footprint. Unfortunately the impact of “ecological comparative advantage” can not be explored without obtaining land and energy intensity figures for exporting countries.

The implicit assumption that all sources and sinks ultimately relate to land based ecosystems may also be considered a general weakness of the ecological footprint. The exploitation of marine resources, for example, is not fully reflected in the current calculations. In theory the ecological footprint may be extended to account for non-land based natural capital such as fisheries and the atmosphere, but this does not yet appear to have been done. Despite this problem it is important to recognise the contribution that the ecological footprint does make. Given that there are currently no comprehensive indicators of sustainability, the ecological footprint provides a valuable conceptual link between economic activity generated by consumption and the land that we rely on for production and waste assimilation.

Standard ecological footprint calculations also imply that current land use practices are sustainable. In many instances this is clearly not the case. Unsustainable practices can not, by definition, continue indefinitely and would at some point have to show up in the ecological footprint. In the meantime such practices distort the short-term picture implied by the ecological footprint. Wackernagel and Rees suggest that adjustments for unsustainable practices may be made by multiplying the ecological footprint by a "sustainability factor". The magnitude of this factor could vary according to the degree of sustainability in existing practices, but in reality it would be difficult to determine. 
Wackernagel and Rees (1996) suggest that a key strength of ecological footprint analysis in general is its conceptual simplicity. It incorporates a great deal of information into a single, readily understandable index which facilitates the promotion of the sustainability concept and the inclusion of ecological impacts in decision making. The benefits of aggregation and conceptual simplicity, however, may be offset to some extent by a lack of specificity. The simultaneous incorporation of the level and composition of consumption, production technology, and the productivity of natural resources, for example, may be a hindrance to identifying specific unsustainable practices. Despite this lack of specificity the ecological footprint does represent a useful attempt to measure progress towards the goal of sustainability when very few alternative yardsticks exist.

The simplifying assumptions discussed in this section are an unavoidable consequence of the modelling process, and data limitations. Their impact on the size of the ecological footprint is difficult to assess without further analysis. It should be noted that many of the data problems represent a practical difficulty, rather than a conceptual problem, and could be eliminated with additional information.

\section{Conclusion}

This paper presents a novel way to calculate the ecological footprint, using data that is collected in most developed countries as part of the system of national accounts. Consequently analysts using this methodology should be able to meaningfully compare ecological footprint estimates among countries, and through time. The use of a national transaction table also emphasises the link between the level of economic activity and a population's impact on the environment, and the connection between the level of final demand and land intensive production processes. A particular strength of the proposed methodology is that it allows a detailed exploration of a country's ecological balance of trade, and provides an indication of how reliant a particular population may be on imports to sustain consumption.

The empirical application presented above suggests that New Zealand's ecological footprint does not exhaust the amount of ecologically productive land currently available within the country. Many overseas countries, by contrast, are currently running extreme ecological 
deficits. Previous studies reveal that aggregate consumption in the United States requires almost twice the ecologically productive land available within the national borders, and the ecological footprint of the average person in Holland is more than 20 times the land available on a per capita basis (Wackernagel and Rees, 1996). While New Zealand's favourable ecological position may be largely attributable to a low population density, per capita consumption is also lower here than in many developed countries.

As calculated above, the ecological footprint yields a consistent bio-physical measure of current levels of consumption to complement the monetary measures that already exist. It therefore provides a conceptually simply, intuitively appealing way to incorporate sustainability goals into the planning process. Although the ecological footprint does not represent economic or social welfare, it does reflect ecological well-being and gives an indication as to whether current consumption and production patterns are likely to be sustainable. 


\section{References}

Barker, W.H. (1978): Assessing the human carrying capacity of New Zealand: A thesis presented in partial fulfilment of the requirements for the Degree of Master of Science in the University of Canterbury. Joint Centre for Environmental Sciences, University of Canterbury and Lincoln College.

Bartelmus, Peter (1994): Environment. Growth \& Development: the concept and strategies of sustainability. London \& New York: Routeledge.

Bullard, CW, PS Penner and DA Pilati, "Net Energy Analysis; Handbook for Combining Process and Input-output Analysis:, CAC Document 214, Centre for Advanced Computation, University of Illinios, October 1976.

International Energy Agency (IEA): Energy Polices of IEA Countries: 1992 Review. Paris: OECD

Leontief, W (1970) "Environmental repercussions and the economic structure: an inputoutput approach”, The Review of Economics and Statistics vol 52(3).

Leontief, W (1986) Input-output Economics, 2nd ed. New York: Oxford University Press.

Miernyk, W.H. (1965) The elements of input-output analysis New York: Random House.

Pearce, David (1994): Blueprint 3: Measuring sustainable development. London: Earthscan.

Peet, John (1991): The use of input-output methods to evaluate the energy requirements and environmental consequences of economic activity: a practical introduction. University of Canterbury, Christchurch, New Zealand.

Transit New Zealand (1994): Road Statistics for the Year Ending June 1994._Wellington.

Statistics New Zealand (Various Years) New Zealand Official Yearbook Auckland: Statistics New Zealand.

Wackernagel M, J McIntosh, WE Rees and R Woollard (1993): How big is our ecological footprint?: A handbook for estimating a community's appropriated carrying capacity (discussion draft of the Task Force on Planning Healthy and Sustainable Communities) University of British Columbia.

Wackernagel , M and W Rees (1996). Our Ecological Footprint: Reducing Human Impact on the Earth, Gabriola Island, BC: New Society Publishers. 